\title{
Man Versus Machine: Resisting Automation in Identity-Based Consumer Behavior
}

Journal of Marketing Research 2018, Vol. 55(6) 818-83। (C) American Marketing Association 2018 Article reuse guidelines: sagepub.com/journals-permissions DOI: 10.1 I 77/00222437|88|8423 journals.sagepub.com/home/mrj

๑SAGE

\author{
Eugina Leung, Gabriele Paolacci, and Stefano Puntoni
}

\begin{abstract}
Automation is transforming many consumption domains, including everyday activities such as cooking or driving, as well as recreational activities like fishing or cycling. Yet little research in marketing examines consumer preferences for automated products. Automation often provides obvious consumption benefits, but six studies spanning a variety of product categories show that automation may not be desirable when identity motives are important drivers of consumption. Using both correlational and experimental designs, these studies demonstrate that people who strongly identify with a particular social category resist automated features that hinder the attribution of identity-relevant consumption outcomes to themselves. The findings have substantial theoretical implications for research on identity and technology, as well as managerial implications for targeting, product innovation, and communication.
\end{abstract}

\section{Keywords}

automation, identity, technology, self, attribution

Online supplement: https://doi.org/I0.I I77/00222437/88/8423

Many of today's products are yesterday's science fiction. Just a few years ago, it was hard to imagine mass diffusion of domestic robots or voice-controlled virtual assistants. Products also are increasingly able to automate tasks that consumers previously had to perform themselves. A new generation of cooking machines can prepare ingredients and implement hundreds of recipes (e.g., Vorvex's Thermomix "does all the hard work and you're along for the ride"); Google's self-driving cars have already raveled millions of miles on U.S. roads. These two innovations are recent examples of a decades-long trend toward increasing automation in both cooking (e.g., food processors) and automotive (e.g., automatic transmission) contexts, and this trend appears bound to increase. IBM, Google, and Intel have acquired start-ups dedicated to artificial intelligence, a crucial technology in the development of autonomous products and services, reflecting the vast efficiency gains that automation can provide consumers. Automation frees consumers from the need to perform tasks that require time and energy, so they can expend fewer resources while still achieving outcomes that match, or even exceed, those obtained without automation.

Despite these unquestionable advantages, automation may not be universally desirable. Anecdotally, some products with automated features evoke controversy among hobbyists and fans in areas as diverse as fishing (sonar fish finders) and baking (bread-baking machines). We posit that automation may be more desirable when people seek to maximize convenience, yet it is not inherently valuable in the case of identity-based consumption. A key idea that has emerged from three decades of consumer research is that consumption decisions are often rooted in people's desire to confirm and express who they are (Reed et al. 2012). If consumers strongly identify with a particular social category, they may resist automated features if the features themselves hinder the attribution of identityrelevant consumption outcomes to the self. By manifesting the skills associated with a given identity, automation removes consumers' ability to internalize the outcomes of the consumption experience, so it is detrimental for identity-based consumption. For example, relying on a bread-baking machine prevents the user from being able to attribute the quality of the resulting bread to her or his knowledge of baking conditions and ability to shape the bread. If identity motives determine the decision to make bread, it should make bread-baking machines less desirable.

To test these ideas, we conducted six studies spanning a variety of product categories (vehicles, fishing devices, kitchen appliances), methods (surveys of real choices, experiments), and samples (online and offline participant pools). We make

Eugina Leung is a doctoral candidate (email: leung@rsm.nl), Gabriele Paolacci is Associate Professor of Marketing (email: gpaolacci@rsm.nl), and Stefano Puntoni is Professor of Marketing (email: spuntoni@rsm.nl), Rotterdam School of Management, Erasmus University. 
several contributions. First, we contribute to the literature on automation. Economists and sociologists who highlight the phenomenon of automation (Erikson 1986; Parasuraman and Riley 1997; Rifkin 1996) mainly take a supply-side perspective and examine the consequences of production automation for workers, unemployment, and societal welfare. In contrast, we focus on the consequences of automation in a consumption domain and highlight some previously undocumented effects of automation in the marketplace. Second, we contribute to technology-related marketing literature by complementing existing research on the dark side of technology (e.g., Etkin 2016; Mick and Fournier 1998; Wilcox and Stephen 2013) and answering recent calls for studies of how technology affects identity-based consumer behavior (Reed et al. 2012). Third, we contribute new theory on consumer identity. Vast literature on identity-based consumption predominantly focuses on how product choice and product displays can enable consumers to express who they are and the groups to which they belong (Belk 1988; Oyserman 2009a; Reed et al. 2012). Yet there is more to identity-based consumption than acquiring or displaying products. "Performing" an identity often requires a specific set of skills and identity-relevant tasks (Oyserman 2009b; Reed et al. 2012); for example, fishing products help anglers construct their identity by enabling a specific behavioral repertoire, including baiting, casting, and reeling. We contribute to the identity literature by highlighting the importance of internal attribution of consumption outcomes in identity-based consumption.

Furthermore, this study offers important guidelines for marketers. Automation has been a crucial trend in consumer markets for decades, but academic marketing research provides little practical guidance. Our findings offer actionable insights at the planning and R\&D stages of the product development process. Product-centric firms should recognize automation as a means to increase efficiency in product usage but also realize that it may constrain the success of identityrelevant products. Customer-centric firms should consider their target segments' identity motives when deciding which tasks, currently performed by consumers, are good candidates for automation initiatives. Then at the product launch stage, managers should determine whether emphasizing internal attribution of consumption outcomes in communication and advertising would increase product adoption likelihood among identity-motivated consumers.

\section{Automation: From Production to Consumption}

Social scientists have been interested in the phenomenon of automation since the Industrial Revolution. The division of labor in the assembly line made it possible for work to be performed by machines, with decreasing engagement by human workers. In his Economic and Philosophic Manuscripts of 1844, Karl Marx famously contended that mechanization alienates workers by depriving them of the meaning of their work. Since then, machines have vastly improved in their sophistication and effectiveness, as (cheaper) replacements of human labor. Today, scholars in economics and related disciplines engage in intense debates about the effects of the current wave of automation on labor markets, often focused on employment effects.

Many economists stress that throughout history, automation has not only substituted but also complemented human labor (e.g., Autor 2015), ultimately creating more jobs than it destroys. Others are less optimistic and claim that automation increasingly takes forms (i.e., artificial intelligence) that might make human labor obsolete and dehumanize society as a whole (cf. Mokyr, Vickers, and Zeibarth 2015). These issues are highly polarizing modern topics, with broad resonance outside academic circles (Brynjolfsson and McAfee 2014; Ford 2015; The Economist 2016). We complement this debate by taking a different angle on automation in the marketplace. How do consumers react to product features that automate consumption tasks that they would otherwise perform?

Considering the ubiquity of automated products, it is tempting to conclude that consumers always value automation. Using cooking machines and electric bikes frees up their time and energy, so consumers can spend them on other activities. Ceteris paribus, automation should improve the benefit-cost trade-off by reducing the costs of consumption but producing similar benefits. However, a perspective that assumes that consumers solely maximize the final outcomes of consumption is overly simplistic, because consumers pursue other motives as well. In particular, consumers care about not just the outcomes of consumption but also the process that leads to those outcomes (Frey and Stutzer 2005). They might climb mountains for the view but also for the challenge of getting to the top (Loewenstein 1999). Automation positively affects consumption outcomes by making them easier to achieve, but when consumption is driven by identity motives, consumers may resist automated products.

\section{Identity and the Diagnosticity of Consumption}

Consumer behavior is often driven by identity motives, as documented in psychology and marketing research. Identity refers to any category label with which the consumer selfassociates (Reed et al. 2012). This category label represents what "kind" of person the consumer is, as well as the behaviors in which she or he engages (Oyserman 2009b). People are inherently motivated to construct their identities (Oyserman 2009a) and use products to confirm and express the identities they hold (e.g., Belk 1988; Berger and Heath 2007; Weiss and Johar 2013). An important factor that influences whether consumers engage in identity-based consumption is the chronic accessibility of the identity, typically referred to as the strength of identification (Deshpandé and Stayman 1994). Greater strength of identification makes consumers more sensitive to information relevant to an identity (e.g., cues in advertising), more likely to purchase identity-relevant products (e.g., Deshpandé, Hoyer, and Donthu 
1986), and more likely to engage in behaviors that directly implicate the identity (Reed et al. 2012).

Strong identifiers value the opportunity to engage in behaviors associated with their target identity, because these behaviors act as signals to the self (Bem 1972; Bodner and Prelec 2003; Khan and Dhar 2006). According to self-signaling theory (Bodner and Prelec 2003), choices depend on outcome utility (associated with the outcomes of consumption) and diagnostic utility (knowing the type of person one is). Consumers can boost their diagnostic utility by taking identity-relevant actions to self-signal that they hold certain identities, which may be independent of outcome utility. Psychologically, the signaling utility of performing identity-relevant activities increases through a process of internal attribution. According to attribution theory, people adopt either internal or external explanations for a given outcome (Cheng and Novick 1990). Internal attribution requires the experience of agency and control over actions (Menon et al. 1999); people cannot credit their own actions as a cause of outcomes when they do not have control over the process. When consumers have low feelings of control, they tend to be less open to new products, perhaps because those products challenge their perceived mastery (Faraji-Rad, Melumad, and Johar 2017), but they prefer products that require more effort, because these products allow the consumers to establish internal attribution for positive outcomes (Cutright and Samper 2014).

Although the desire for internal attribution of positive outcomes is a robust psychological tendency, it is by no means uniform (Mezulis et al. 2004). In an identity domain, strong identifiers have an especially high need for internal attribution, so they value the self-signaling utility of performing tasks that are diagnostic of their identity. A factor that characterizes the degree to which a consumption activity is diagnostic of the consumer's identity is its "difficulty," or degree to which it requires using acquired skills or exerting effort (Stets and Burke 2000). Because difficult activities are by definition less attainable by people who lack skills or will not put forth effort, they become particularly diagnostic of the identity of those who are able and willing to perform them. In summary, strong identifiers can harness the self-signaling utility of consumption by internally attributing consumption outcomes to their own skillful or effortful actions.

\section{Identifiers Resist Automation}

Automation often replaces skills that are instrumental to selfsignaling an identity. For example, a bread-baking machine bakes the bread automatically with minimal involvement from users. The machine provides instructions about the ingredients, and it controls the temperature and timing, so it replaces skills essential to the baker identity. When automation replaces skill or effort, it removes opportunities for internal attribution. Thus, we predict that strong identifiers find products less appealing if they automate identity-relevant tasks, because these strong identifiers have a higher need for internal attribution. We also consider two important qualifications.
First, we do not argue that strong identifiers are modern-day Luddites; they are not opposed to technology per se. Automating tasks that are not especially diagnostic of their identity should not prevent internal attribution of consumption outcomes, in which case strong identifiers likely do not oppose this form of automation. Dough-kneading machines automate the repetitive task of kneading the dough prior to baking, a task that does not necessarily distinguish skilled from less skilled bakers. Therefore, many amateur bakers might resist breadbaking machines but not dough-kneading machines. This proposition parallels the finding that healthy young people are more reluctant to take pharmaceutical enhancements when those enhancements affect fundamental psychological traits than when they do not (Riis, Simmons, and Goodwin 2008).

Second, our arguments do not imply that people's consumption motives are the same across situations. Strong identifiers should be opposed to automation only when they consume in the target product category for identity reasons. If a consumer is motivated by non-identity reasons (e.g., convenience), automation may be valued similarly by strong identifiers and weak identifiers. For example, a keen cyclist may decide to buy another bike to commute to work to avoid slow traffic or save money. In this situation, the consumer may be attracted by features like a battery pack for assisted pedaling, to make the ride to work faster or avoid arriving sweaty to the office, even if the same person would never consider such automation when buying a bike to use on recreational weekend rides. This proposition is consistent with a view of consumer choice as driven by the relative activation of different goals (van Osselaer et al. 2005).

In the reminder of this article, we present a series of studies to demonstrate that strength of identification is an important determinant of preferences for automation in identity-relevant contexts (see Table 1). The findings provide insights into why and when this determination is the case. In all studies, the data collection was subjected to predetermined stopping rules (target sample sizes in online studies; number of experimental sessions in lab studies). We excluded no participants from the analyses unless specified, and we report the results for all conditions and dependent measures collected.

\section{Study I: Driving}

Study 1 has two objectives. The first is to test our key proposition by examining the link between strength of identification and actual choices of automation in identity-relevant contexts. This study deals with cars, and in particular, drivers' choices to purchase a car with manual or automatic transmission. In cars with manual transmissions, the driver must change gears by pressing the clutch pedal and moving the gear lever. In cars with automatic transmissions, a computer changes gears, and the driver does not need to perform any action. A manual transmission allows drivers to affect the engine's torque directly, and the act of shifting gears may offer self-signaling utility to consumers who are interested in driving per se, rather than as a means of transportation. For example, Spyker Cars, a 
Table I. Study Results.

\begin{tabular}{|c|c|c|c|}
\hline Study & Context & Participants & Key Variables \\
\hline I & Driving & $\begin{array}{l}\text { Phase I: } N=2,444(I, I I 9 \\
\text { women, } M_{\text {age }}=31.0 \text { years, } \\
\text { US, Prolific) } \\
\text { Phase } 2: N=150 \text { ( } 55 \text { women, } \\
\left.M_{\text {age }}=40.13 \text { years }\right)\end{array}$ & $\begin{array}{l}\text { Independent: Strength of } \\
\text { identification (driving) } \\
\text { Dependent: Transmission } \\
\text { type of the car owned }\end{array}$ \\
\hline 2 & Biking & $\begin{array}{r}N=338 \text { (I83 women; } M_{\text {age }}= \\
\text { I9.8 years, undergraduates })\end{array}$ & $\begin{array}{l}\text { Independent: Identity salience } \\
\text { Dependent: Choice of free } \\
\text { automated feature }\end{array}$ \\
\hline
\end{tabular}

\begin{tabular}{ccc}
\hline Identity-salient & Control \\
\hline $66 \%$ & $78 \%$ \\
\hline
\end{tabular}

Participants in the identity-salient condition are less likely to accept the offer of a free automated feature than those in the control condition.

3 Baking $\mathrm{N}=403$ (I73 women, $\mathrm{M}_{\mathrm{age}}=$ 33.0 years, U.S., MTurk)

Fishing $\quad N=305$ (137 women, $M_{\text {age }}=$ 34.2 years, U.S., MTurk) 34.9 years, U.S., MTurk)

Cooking $N=402$ (203 women, $M_{\text {age }}=$ 19.8 years, undergraduates)
Independent: Level of skill required of the automated task

Moderator: Strength of identification

Mediator: Internal attribution

Dependent: Willingness to borrow the automated machine

Independent: Strength of identification (fishing)

Mediator: Internal attribution

Dependent: Choice of automated fishing rod

Independent: Consumption motive

Dependent: Choice of free automated feature on a bike

\begin{tabular}{|c|c|c|c|}
\hline \multicolumn{2}{|c|}{ More skill required } & \multicolumn{2}{|c|}{ Less skill required } \\
\hline Strong identity & Control & Strong identity & Control \\
\hline $\begin{array}{c}.12 \\
(2.00)^{\mathrm{a}}\end{array}$ & $\begin{array}{c}1.52 \\
(1.6 I)\end{array}$ & $\begin{array}{c}1.08 \\
(1.83)\end{array}$ & $\begin{array}{c}1.25 \\
(1.7 I)\end{array}$ \\
\hline
\end{tabular}

Greater strength of identification leads to decreased acceptance of automation in identity-relevant contexts, though not when the automated task requires less skill.

\begin{tabular}{ccc}
\hline Strong identity & Control \\
\hline $45 \%$ & $61 \%$ \\
\hline
\end{tabular}

Desire for internal attribution mediates the effect of identification on choice $(b=-.13, S E=.13,95 \%$ confidence interval: -.42 to .12$)$.

\begin{tabular}{ccc}
\hline Identity motive & Non-identity motive \\
\hline $57 \%$ & $80 \%$ \\
\hline
\end{tabular}

Strong identifiers are less likely to prefer automation when identity motives are important.

\section{Independent: Product framing No automation Skill-replacing Skill-allowing \\ Moderator: Strength of identification (cooking) \\ Dependent: Liking of the

\begin{tabular}{ccc} 
No automation & $\begin{array}{r}\text { Skill-replacing } \\
\text { automation }\end{array}$ & $\begin{array}{r}\text { Skill-allowing } \\
\text { automation }\end{array}$ \\
\hline $\mathrm{b}=.18$ & $\mathrm{~b}=-.33$ & $\mathrm{~b}=.060$
\end{tabular}
cooking machine
Strong identifiers resist automation when it is framed as skill replacing but not when it is framed as skill-allowing.

\footnotetext{
${ }^{\mathrm{a} S t a n d a r d ~ d e v i a t i o n s . ~}$
}

niche Dutch company targeting driving enthusiasts, resisted introducing automatic transmissions for years, due to concerns about this feature's inconsistency with the practice of skillful driving. (The company eventually relented because the lack of automatic transmissions was impeding sales in China.) Thus, we predict that people with a stronger identification with driving are more likely to own a car with a manual transmission.

The second objective is to demonstrate that identification predicts automation choices, rather than other potential explanations of this effect. For example, in most cases, strength of identification correlates with expertise, so the effect of identification arguably could stem from the greater ease with which strong identifiers operate manual transmissions. Moreover, strong identifiers might be more likely than weak identifiers to perceive the outcomes of the automation as worse than those without automation, such that they resist automation because they do not trust it. With this study, we aim to show that identification remains a significant predictor of automation choice, even after controlling for participants' expertise and outcome beliefs.

\section{Method}

Study 1 consists of two phases. In phase one, we conducted a survey to measure the independent variable (strength of 
identification) and other relevant screening variables (e.g., possessing a driver's license). In phase two, we recruited participants from phase one who fulfilled the screening criteria and collected the focal dependent and control variables, as well as two potentially relevant variables that correlate with identity strength (i.e., expertise) and automation (i.e., the expected performance of automatic vs. manual transmissions).

In phase one, we recruited 2,431 participants with U.S. nationality on Prolific ( 1,119 women, $\mathrm{M}_{\text {age }}=31.0$ years, SD $=11.15$ ), an online participant pool that provides high-quality data for behavioral research (Peer et al. 2016). This study phase spanned four months (December 2016 to March 2017). Participants were asked to complete a study that contained two parts. The first part was an unrelated study; the second part included the focal measures. To support the cover story that the investigation sought a survey of personal interests, participants rated their interest in a range of hobbies and activities (e.g., baking, gaming). This part also included a measure of strength of identification, according to respondents' agreement with three statements: "I am really into driving," "I identity myself as a driver," and "Driving is one of my favorite hobbies" (seven-point scale; $\alpha=.88$ in the final sample; see Web Appendix A). Participants also answered a few questions about driving and car ownership, as eligibility criteria for the second phase.

Phase two started two months after the end of phase one (i.e., May 2017). The study description made no reference to the previous survey. The time between the measures of the independent and dependent variables thus ranged between two and six months. In the second phase, we invited all 267 participants who satisfied several criteria to participate (96 women, $\mathrm{M}_{\mathrm{age}}=38.1$ years, $\mathrm{SD}=12.24$ ). To be eligible for inclusion in our final sample, participants had to (1) have a driving license and own a car; (2) be the person in the household who chose the car (to be able to match driver's strength of identification and car choice); (3) have bought a new car (vs. used, to minimize the role of irrelevant situational concerns such as bargain hunting; Guiot and Roux 2010); and (4) know how to operate a manual transmission. We obtained a $56 \%$ response rate, resulting in a final sample of 150 participants (55 women, $\mathrm{M}_{\text {age }}=40.1$ years, $\left.\mathrm{SD}=12.60\right)$. There was no difference in strength of identification as drivers between those who responded to our invitation to participate in the phase two survey and those who did not $(p=.27)$.

Participants first indicated their agreement with five statements measuring driving expertise (randomized order, $\alpha=$ .82 ). Two items ("I can shift gears easily according to the driving conditions," and "I can use the clutch easily while changing gears," $\mathrm{r}=.79, p<.001)$ measured expertise in operating a manual transmission, and their average provides a separate, additional measure of expertise. The other three statements investigated participants' expertise with other aspects of driving (see Web Appendix B). Participants then rated outcome quality on three dimensions: reliability, likelihood of breaking down, and performance (bipolar scales, $1=$ manual transmission, $7=$ automatic transmission; Web Appendix B). The reliability of an aggregate measure of these three outcomes items is barely acceptable $(\alpha=.68)$. We report analyses conducted using both an aggregated outcome scale and the three items separately. Finally, participants reported how many cars they owned and were asked to focus on their preferred car. For this car, participants reported its age, brand, and, critically, type of transmission (automatic or manual).

\section{Results and Discussion}

Most participants (77\%) owned a car with an automatic transmission. We conducted a logistic regression using the type of transmission as a dependent variable and strength of identification as an independent variable. Consistent with our prediction, participants who identified more strongly as car drivers were more likely to own a car with a manual transmission $(\mathrm{b}=.29$, Wald $=4.93, p=.026)$. When we include manual transmission expertise and the three perceived outcome quality items as covariates, we find that participants who perceive the manual transmission as less likely to break down and to perform better under most situations are more likely to own a car with a manual transmission $\left(\mathrm{b}_{\text {Breakdown }}=-.33\right.$, Wald $=4.66$, $p=.031 ; b_{\text {Performance }}=-.44$, Wald $\left.=6.39, p=.011\right)$. Manual transmission expertise does not predict choice $(p>.12)$. Stronger identification as a driver still predicts the likelihood of owning a car with a manual transmission after we control for expertise and perceived outcome quality $(\mathrm{b}=.29$, Wald $=$ 4.04, $p=.044)$. We obtain similar results when we control for general driving expertise instead of manual transmission expertise $(\mathrm{b}=.28$, Wald $=3.86, p=.049)$ and for the aggregated perceived outcome scale instead of the three perceived outcome quality items separately $(\mathrm{b}=.31$, Wald $=4.75, p=$ $.029)$. In addition, strength of identification does not significantly correlate with any of the expertise or outcome quality items (all $p>.24)$. Importantly, strength of identification remains a significant predictor of transmission choice, even after controlling for a host of factors (e.g., if car was a luxury car, manufacturer's origin, age, gender; Web Appendix C).

In summary, Study 1 documents an association between strength of identity as a car driver and likelihood of owning a car with a manual transmission. Cars are a very expensive product owned by many consumers, and in this category, automation is likely to increase vastly in coming years. With our two-phase design, this study avoids the inclusion of imposters, by disguising the study eligibility criteria (Chandler and Paolacci 2017) and by separating the measures of the independent and dependent variable by several months. We can rule out an alternative explanation that suggests strong identifiers dislike automation simply because they have more expertise or perceive the outcomes of automatic transmissions as inferior. We measured these alternative accounts immediately prior to the dependent variable, whereas we measured the key independent variable several months earlier. The robustness of the effect of strength of identification on transmission choice thus is notable. 


\section{Study 2: Biking}

Study 2 documents the link between strength of identification and preferences for automation using an experimental approach that manipulates identity salience. In this study, we focus on a different consumption domain: bicycling.

\section{Method}

Three hundred thirty-eight Dutch students (183 women; $\mathrm{M}_{\text {age }}=19.8$ years, $\mathrm{SD}=1.35$ ) at a major Dutch university participated in this lab study in exchange for course credit. Following previous research, we manipulated identity salience using essay writing tasks, an approach that has been used successfully to increase the accessibility of stable and important identities (e.g., gender identity among women; Puntoni, Sweldens, and Tavassoli 2011). We manipulated strength of identification by randomly assigning participants to write about either the role of biking in their life (identity-salient condition) or the role of a biking-irrelevant factor (control condition). We selected biking as the study context because it is an activity that virtually all Dutch university students perform regularly (daily, in most cases) but for different reasons and with different levels of involvement. For some students, biking is just a cheap and efficient way to go from one place to another, whereas for others it is a hobby. In the identity-salient condition, participants were asked to spend five minutes reflecting on what the Dutch biking culture meant for them. In the control condition, participants read the same instructions but focused on another stereotypical Dutch passion, namely, flowers. Next, participants read a bike purchase scenario in which they encountered an advertisement in a bike shop and decided to buy the bike. A special offer would allow them to have an automated feature (rechargeable battery that assists pedaling) installed on the bike without any extra charge. Participants indicated whether they wanted to add this (free) feature. As a control for biking experience, they also noted whether they knew how to ride a bike, how often they rode, and for how long they had been riding.

\section{Results and Discussion}

Two participants did not know how to ride a bike and were excluded from the analysis. The majority of the participants used a bike every day (62\%) and had been biking for more than ten years $(98 \%)$. Participants in the two conditions did not differ in terms of frequency of bike use $(p=.26)$ or years of experience in biking $(p=.69)$. In total, $72 \%$ of the participants chose to install the free automated feature, yet $78 \%$ of the participants in the control condition chose to include it, whereas only $66 \%$ of the participants in the identity-salient condition did so $\left(\chi^{2}=\right.$ $5.79, p=.016)$. These results replicate the previous findings with an experimental approach, ensuring that identification does not correlate with confounding variables such as expertise and experience with biking. Study 2 also helps address the alternative explanation that identifiers simply enjoy performing the focal task more. In this case, the focal task (pedaling) needs to be performed even in the presence of automation (albeit with less effort at the same speed or a faster speed with the same effort), and people do not need to use assisted pedaling if they choose not to at a particular moment.

To explore the generalizability of these findings, we replicated the results using a correlational study (Web Appendix F). Instead of priming biking identity, we measure identification with a self-reported measure similar to the one from Study 1. Again, we find a negative association between strength of identification and willingness to accept the free battery pack $(\mathrm{N}=120 ; \mathrm{r}=-.20, p=.027)$.

\section{Study 3: Baking}

Strong identifiers may resist automating tasks because doing so prevents internal attribution of consumption outcomes, ultimately frustrating identity goals. In turn, strong identifiers should resist automation that replaces skills that are central to their identity but not automation that does not do so. Study 3 tests this prediction to provide initial evidence of the role of internal attribution.

In a baking scenario, participants could borrow equipment to make bread; we test whether strength of identification predicts preference for automation differently depending on how much skill the automated task would require if performed by the user. Strong identifiers likely resist automation that drastically reduces the skills required to bake the bread (i.e., breadbaking machine) but not automation that does not (i.e., a machine that only mixes the dough, something that virtually anybody can do). We expect participants to evaluate the two products as differently preventative of internal attribution of consumption outcomes, and strength of identification should moderate the degree to which the possibility for internal attribution predicts willingness to borrow the equipment. Accordingly, lower internal attribution should lead to a lower likelihood of borrowing among strong identifiers relative to weak identifiers. Formally, we use the product as an independent variable and identity strength as a moderator, such that we test a moderated mediation model, with prevention of internal attribution as the mediator.

We pretested varying amounts of skill involved in bread baking and dough mixing among $101 \mathrm{U} . \mathrm{S}$. residents recruited on Amazon Mechanical Turk (MTurk) (57 women, $\mathrm{M}_{\text {age }}=$ 33.1 years, $\mathrm{SD}=9.33$ ). Participants read the descriptions of bread baking and dough mixing on separate pages and in random order, then rated the amount of skill involved in each task on a 7-point scale ( 1 = "No skill is involved," 7 = "A great deal of skill is involved"). The paired-samples t-test revealed that bread baking was perceived as requiring more skill than dough mixing $\left(\mathrm{M}_{\text {Baking }}=5.06, \mathrm{SD}=1.24, \mathrm{M}_{\text {Mixing }}=4.44, \mathrm{SD}=1.45\right.$; $\mathrm{t}(100)=-3.55, p<.001)$.

\section{Method}

Four hundred six U.S. residents recruited on MTurk (161 women, $\mathrm{M}_{\mathrm{age}}=32.7$ years, $\left.\mathrm{SD}=10.02\right)$ were randomly 
assigned to one condition of a 2 (strength of identification: strong identification vs. control) $\times 2$ (automated task: more vs. less skill required) between-participants design. We manipulated strength of identification by prompting half of participants with identification information. In the strong identification conditions, they read: "Imagine you are a keen amateur bread baker. Although your skills are far from professional, you are very serious about baking. You are proud of yourself as a bread baker. You spend most of your free time baking and you enjoy baking." Participants in the control conditions did not read this description. All participants read: "Today you are planning to make a loaf of bread. Suppose you do not have all the equipment needed for the baking task. You can get some equipment from a friend living next door."

Participants next read the description of one product. In the more skill required conditions, they read: "Jones Bread-Maker bakes the bread for you. There is a display screen showing you which ingredients you need, their corresponding amount, and the order to put the ingredients into the bread-maker. You just need to put your ingredients into the bread-maker. Once you press the "start' button, a loaf of bread will be ready soon." In the less skill required conditions, participants read: "Jones Dough-Mixer kneads the dough for you. This dough-mixer has various timers and controls. You can just put the ingredients into the dough-mixer according to your recipe. Once you press the 'start' button, the dough will be ready soon." Participants indicated their willingness to borrow the equipment $(-3=$ "Definitely will not borrow," $0=$ "Indifferent," $+3=$ "Definitely will borrow"). We use borrowing as a context to avoid potential confounds of irrelevant purchase considerations. We also measure the extent to which the product prevents internal attribution (agreement that by using the product, "I cannot claim that the bread was well-made because of my baking ability," seven-point scale).

\section{Results and Discussion}

A $2 \times 2$ analysis of variance (ANOVA) with willingness to borrow (WTB) as the dependent variable reveals a main effect of strength of identification (WTB is lower in the strong identification condition; $\mathrm{F}(1,402)=19.52, p<.001)$, a main effect of automated task (WTB is lower in the less skill required condition, $\mathrm{F}(1,402)=3.76, p=.053)$, and a significant interaction $(\mathrm{F}(1,402)=11.91, p=.001$; see Figure 1$)$. Consistent with our hypotheses, when the automated task requires more skill to perform manually (bread baking), WTB is lower in the strong identification condition than in the control condition $\left(\mathrm{M}_{\text {Strong }}=.12, \mathrm{SD}=2.00 ; \mathrm{M}_{\text {Control }}=1.52, \mathrm{SD}=1.61\right.$; $\mathrm{F}(1,402)=30.96, p<.001)$. However, when the automated task requires less skill (dough mixing), WTB does not differ between strong identifiers and control participants $\left(\mathrm{M}_{\text {Strong }}=\right.$ $1.08, \mathrm{SD}=1.83 ; \mathrm{M}_{\text {Control }}=1.25, \mathrm{SD}=1.71 ; \mathrm{F}(1,402)=.47$, $p=.50)$. In addition, the dough mixer provides more potential for internal attribution than the bread baker $\left(\mathrm{M}_{\text {Mixer }}=5.13\right.$, $\mathrm{SD}=1.68 ; \mathrm{M}_{\text {Baker }}=3.69, \mathrm{SD}=1.84 ; \mathrm{t}(404)=8.22$, $p<.001)$. We also conduct a $2 \times 2$ ANOVA with internal

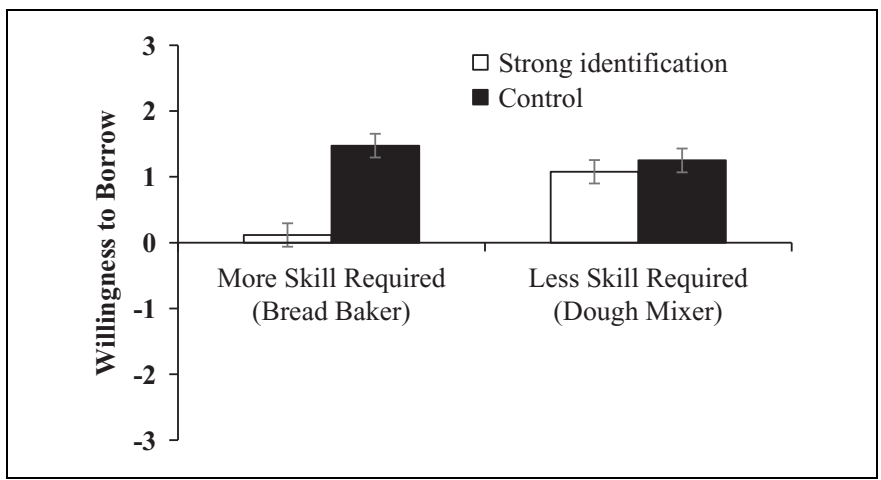

Figure I. Study 3: Identification effects on willingness to borrow automated products.

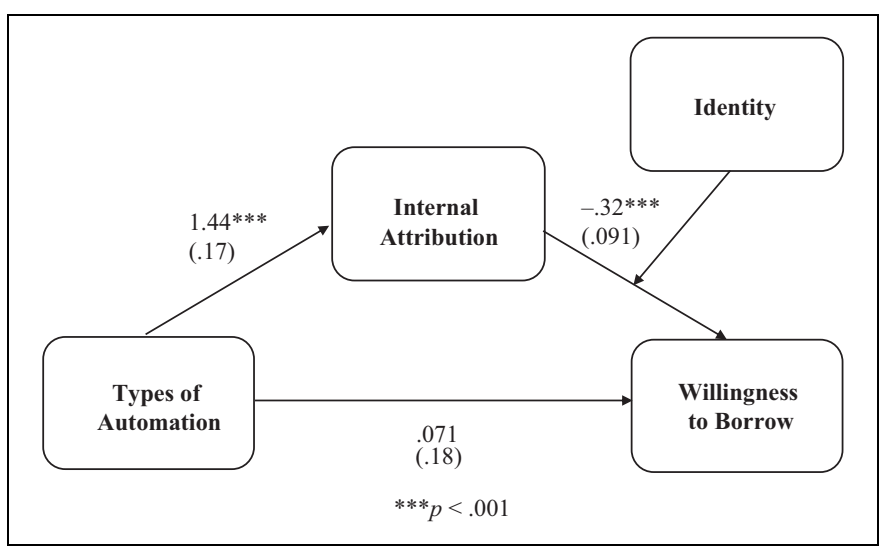

Figure 2. Study 3: Moderated mediation.

$* * * p<.001$.

Notes: Moderated mediation results are based on 5,000 bootstrapped samples ( $95 \%$ confidence interval: -.76 to -.19 ).

attribution and find main effects of identity $(\mathrm{F}(1,402)=6.14$, $p=.014)$ and product $(\mathrm{F}(1,402)=68.40, p<.001)$ but no interaction $(p=.77)$.

Products that automate tasks that require more versus less skill to perform manually thus prevent internal attribution to different extents, which selectively affects WTB among strong identifiers. Statistically, we test this prediction by conducting a moderated mediation analysis using 5,000 bootstrapped samples (Hayes 2012; PROCESS model 14), with the automated task as the independent variable, internal attribution as a mediator, strength of identification as a moderator, and WTB as the dependent variable. The model is significant $(\mathrm{b}=-.46, \mathrm{SE}=$ $.15,95 \%$ confidence interval [CI]: -.76 to -.19 ; Figure 2). Participants consider the bread baker more preventative of internal attribution than the dough mixer $(\mathrm{b}=1.44, \mathrm{SE}=$ $.17,95 \% \mathrm{CI}: 1.09$ to 1.78$)$, which decreases their WTB (b= $-.14, \mathrm{SE}=.067,95 \% \mathrm{CI}:-.28$ to -.00$)$. Internal attribution decreases WTB among participants in the strong identity condition $(\mathrm{b}=-.66, \mathrm{SE}=.12,95 \% \mathrm{CI}:-.91$ to -.45$)$ but not in the control condition ( $95 \% \mathrm{CI}:-.43$ to .02$)$.

These results replicate the finding that greater strength of identification leads to decreased acceptance of automation in 
identity-relevant contexts. Study 3 extends the previous studies by showing that this effect does not hold when the automated task requires less skill, because such automation does not prevent internal attribution of consumption outcomes. We replicate these results in a modified version of this study that controls for inferred expertise and perceived quality of outcomes (Web Appendix J).

\section{Study 4: Fishing}

In Study 4's experiment, we use a simple design to estimate the contribution of internal attribution to the effect of identification on preferences for automation, while controlling for potentially concurrent mediating roles of three alternative variables: expertise, enjoyment, and outcome quality. Participants might believe that, as strong identifiers, they are experts who do not need automation, automation may provide a less enjoyable experience, or it could lead to inferior outcomes. These beliefs might contribute to identifiers' resistance to automation, but we hypothesize that the remaining mediating effect of internal attribution still is significant.

We conducted this study in a fishing context, in which automation is conducive to superior outcomes. In previous studies, we ruled out (by design or statistically) the possibility that the effect is caused by strong identifiers' lack of trust in the automation's ability to do the job as well as they can. In this study, we focus on an automated feature that could yield superior outcomes: a fishing rod with an automatic hook-setting device that can catch fish even if the fishing rod is unattended. Therefore, this automated feature potentially enables users to catch more fish. To isolate the effect of internal attribution, we also include measures of expertise, perceived process enjoyment, and perceived outcome quantity.

\section{Method}

Three hundred five U.S. residents on MTurk (137 women, $\mathrm{M}_{\text {age }}=34.2$ years, $\mathrm{SD}=10.61$ ) were randomly assigned to either an identity condition or a control condition. In the identity condition, the scenario started: "Imagine you used to go fishing with your father during your childhood. You were not particularly skilled. Although you might not have gone fishing in a long time, you still consider yourself a recreational fisherman. Fishing is an important part of who you are even though you are still not particularly good at it." Participants in the control condition read only the first two sentences. Next, all participants read: "Today you are visiting a friend who lives in another city. Your friend suggests going fishing. You can borrow one of the following fishing rods from a fishing store next door: Jones fishing rod is made of fine materials. It is sensitive, making it easy to feel slight movements. Its three-part cork handle allows for a firm grip and great control. Smith fishing rod is made of quality materials. It comes with an automatic fishing hook setting device which attaches to the fishing rod. It automatically sets the fish hook when a fish takes the bait while the pole is unmanned." Participants then chose between the normal rod and the one with the automated feature. Next, they indicated their agreement on seven-point items designed to measure their need for internal attribution $(\alpha=.87)$ : "It would be important for me to know that I catch fish because of my own fishing skills," "It would be important for me to feel proud of the fish I was able to catch," and "It would be important for me to take credit for the fish I caught." We also collected an identity manipulation check (agreement with "I am really into fishing," "I identify myself as a fisherman," and "Fishing is one of my favorite hobbies"; $\alpha=.92$ ), a measure of inferred expertise (agreement with "I am good at fishing," "I know how to fish well," and "I can fish well"; $\alpha=.94$ ), a measure of outcome quality pertaining to how the two fishing rods contribute to catching fish ("Which fishing rod can catch more fish?"; $-3=$ "The Jones fishing rod can catch more fish," $0=$ "The number of fish caught is probably similar between using the above two fishing rods," $+3=$ "The Smith fishing rod can catch more fish"), and a measure of perceived enjoyment ("Which fishing rod would provide a more enjoyable experience?"; $-3=$ "Jones fishing rod would provide a more enjoyable fishing experience," $0=$ "The two fishing rods would provide equally enjoyable fishing experience," $3=$ "Smith fishing rod would provide a much more enjoyable fishing experience").

\section{Results and Discussion}

Participants in the identity condition report a stronger fishing identity $\left(\mathrm{M}_{\text {Strong }}=4.98, \mathrm{SD}=1.52, \mathrm{M}_{\text {Control }}=2.65\right.$, $\mathrm{SD}=1.53, t(303)=13.35, p<.001)$. Replicating the findings of the previous studies, $61 \%$ of participants choose the automated fishing rod in the control condition, but only $45 \%$ do so in the identity condition, a significant difference $\left(\chi^{2}(1)=7.84\right.$, $p=.005)$. Moreover, need for internal attribution is higher in the identity condition than in the control condition $\left(\mathrm{M}_{\text {Strong }}=\right.$ $5.12, \mathrm{SD}=1.43, \mathrm{M}_{\text {Control }}=4.55, \mathrm{SD}=1.69, \mathrm{t}(303)=3.16$, $p=.002)$. In addition, those in the identity condition report higher expertise $\left(\mathrm{M}_{\text {Strong }}=3.56, \mathrm{SD}=1.55, \mathrm{M}_{\text {Control }}=2.42\right.$, $\mathrm{SD}=1.54, t(303)=6.43, p<.001)$ and perceive that the automated rod provides a marginally less enjoyable experience $\left(\mathrm{M}_{\text {Strong }}=-.66, \mathrm{SD}=1.84, \mathrm{M}_{\text {Control }}=-.24, \mathrm{SD}=1.97\right.$, $t(303)=-1.93, p=.054)$. There are no differences in perceived performance between conditions $(p=.26)$. The automated rod is generally perceived to support catching more fish than the non-automated option $(\mathrm{M}=1.20, \mathrm{SD}=1.38$, onesample $t(304)=15.18, p<.001)$.

To test if desire for internal attribution mediates the effect of identification on automation choice, controlling for the potential role of other mechanisms, we conduct a parallel mediation analysis with 5,000 bootstrapping samples (Hayes 2012) with desire for internal attribution, expertise, perceived enjoyment of automation, and outcome quality as competing mediators. Expertise $(\mathrm{b}=-.13, \mathrm{SE}=.13,95 \% \mathrm{CI}:-.42$ to .12$)$, enjoyment $(\mathrm{b}=-.32, \mathrm{SE}=.18,95 \% \mathrm{CI}:-.72$ to .02$)$, and outcome quantity $(\mathrm{b}=-.11, \mathrm{SE}=.11,95 \% \mathrm{CI}:-.37$ to .08$)$ do not mediate the effect of identification on choice, whereas 
participants' desire for internal attribution does so $(b=-.30$, $\mathrm{SE}=.13,95 \% \mathrm{CI}:-.60$ to -.10 ).

In summary, this study replicates the previous findings and adds to the evidence regarding the role of internal attribution, by using a parallel mediation approach. Notably, participants perceive that the automated fishing rod would allow them to catch more fish than the non-automated option, implying that resistance to automation does not depend on inferences that automated options perform worse than non-automated ones.

\section{Study 5: Biking Motives}

The previous studies focus on how choices by weak and strong identifiers differ, without exploring the potential role of situational variability in determining the motivations of high identifiers. However, as highlighted in the theory section, strong identifiers may consume for non-identity reasons, in which case they may display less resistance to automation. Study 5 examines this possibility using a bike purchase scenario that manipulates the motive for buying the bike.

\section{Method}

Two hundred U.S. residents on MTurk (99 women, $\mathrm{M}_{\mathrm{age}}=$ 33.0 years, $\mathrm{SD}=11.69$ ) were randomly assigned to either an identity motive or a non-identity motive condition in a between-participants design. All participants first read: "Imagine you are a keen bike rider. Although your skills are far from professional, you are very serious about biking. You are proud of yourself as a bike rider. You spend most of your free time biking and you enjoy biking. You often visit a bicycle forum to exchange information on different types of bicycles with other members on the forum." Participants in the identity motive condition then read: "Lately you are considering buying a new bicycle for weekend excursions. These excursions feature a few different courses of approximately 10 miles. During these activities, you can enjoy the cycling activities and enhance your skills as a cyclist. You want to minimize your cycling time that is not part of the excursion (e.g., getting to the start)." In the non-identity motive condition, participants instead read: "Lately you are considering buying a new bicycle for commuting to work. The distance between your office and your apartment is approximately 10 miles. You live in a city with congested traffic and riding a bicycle would save you a lot of time to get to the office. You want to minimize the time of the ride to facilitate your commute." Then participants read the same bike purchase scenario as in Study 2 and indicated whether they would like to have the free automated feature on their bike. We predict that participants in the identity motive condition are less likely to choose the free automated feature than those in the non-identity motive condition.

\section{Results and Discussion}

Participants choose the free automated feature more in the nonidentity motive condition than in the identity motive condition $\left(80 \%\right.$ vs. $\left.57 \% ; \chi^{2}(1)=12.94, p<.001\right)$. These results are consistent with our prediction that strong identifiers are less likely to prefer automation when the primary motive of consumption relates to their identity. Moreover, the intrinsic enjoyment of a task is should not change much across situations, so these findings join Studies 2 and 4 in suggesting that greater task enjoyment among high identifiers is not necessary for the key predicted effect to occur.

\section{Study 6: Cooking}

Study 6 aims to show that strong identifiers' resistance to automation is contingent on the product framing, such that they are presented as replacers of skills. If the need for internal attribution drives the documented effect of identification on preferences for automation, automation should be perceived more negatively by strong versus weak identifiers when it is framed as replacing their skills. If instead automation is framed as allowing users to deploy their existing skills, strong identifiers may perceive automation less negatively. Participants in this lab study reviewed an advertisement for kitchen equipment and evaluated its attractiveness. We manipulated whether the automated product was framed as skill replacing (i.e., performing actions the user would otherwise perform) or skill allowing (i.e., enabling users to put their skills to use) and hypothesized that only skill-replacing automation would be perceived as less attractive by strong identifiers, relative to a baseline condition in which the product involves no automation. We pretested the degree to which the products in the main study were perceived to substitute for or complement the user's skills $(\mathrm{N}=99$ participants, from the same pool as the main study, 47 women, $\mathrm{M}_{\text {age }}=19.8$ years, $\mathrm{SD}=1.56$ ). The pretest confirmed the validity of the manipulation, as we detail in Web Appendix N.

\section{Method}

Four hundred two business students participated in this lab study in exchange for course credit (203 women, $\mathrm{M}_{\mathrm{age}}=$ 19.8 years, $\mathrm{SD}=1.59$ ). Participants saw an advertisement for a cooking product and evaluated its attractiveness. In a between-participants design, we manipulated whether the product was a non-automated cooking set, an automated cooking machine framed as replacing the user's skills, or an automated cooking machine framed as allowing the user to deploy existing skills.

In the no automation (baseline) condition, participants read the following description of a cooking set: "Smith Cooking Set is a complete cooking set that includes covered casserole, sauce pan, fry pan, 10-piece knife set, 5-piece nylon tools, a rolling pin, a balance and a thermometer. With this set, you can perform different cooking tasks including weighing, kneading, blending, steaming, cooking, beating, precise heating, and stirring. You can make sauce, soup, salad, pasta, pizza, cake, or sorbet. Cooking has never been easier and more satisfying." In the two automation conditions, participants read the following description of a cooking machine: "Smith Automatic Cooking 
Machine combines nine appliances in one with functions that include weighing, kneading, blending, steaming, cooking, beating, precise heating, and stirring." In the skill-replacing automation condition, the text continued: "You can follow onscreen recipe instructions from sauce, soup, salad, pasta, pizza, cake, or sorbet for a step-by-step guaranteed success. The recipes have been tailor made to work perfectly with the applianceall you need to do is add the ingredients, and Smith Automatic Cooking Machine will set the temperature and timings for you. The entire cooking process is completed for you at the touch of a button. Cooking has never been easier and more satisfying." In the skill-allowing automation condition, the text instead continued: "Apart from following the built-in recipes from sauce, soup, salad, pasta, pizza, to cake or sorbet, you can recreate your own family favorites to create culinary masterpieces. You have complete control over your food and your recipes. You can manually select your time, temperature, and speed. The entire cooking process is accomplished by you with the guidance of the machine. Cooking has never been easier and more satisfying."

Participants indicated how much they liked the product on three items $(1=$ "Dislike a great deal/Extremely negative/ Extremely unfavorable," 7 = "Like a great deal/Extremely positive/Extremely favorable"; $\alpha=.92$ ). We then measured the strength of identification with three items: "I consider myself an amateur chef," "To me, cooking is an important part of my life," and "Cooking defines a central part of who I am" ( 1 = "Strongly disagree," 7 = "Strongly agree"). In contrast with the identification scales used in previous studies, the reliability was low $(\alpha=.56)$ but improved when we dropped the first item $(\alpha=.86$; some participants may have interpreted the word "amateur" in a depreciative sense of being inept). We thus aggregated the second and third items as the cooking identity measure.

\section{Results and Discussion}

We estimate a regression model with the three conditions (baseline, skill-replacing automation, skill-allowing automation condition) and the mean-centered continuous measure of cooking identification as predictors. The baseline condition serves as the reference category, and the dependent variable is product liking. We find a main effect of identification on liking $(\mathrm{b}=.18, \mathrm{t}(396)=2.69, p=.007)$. There also is a marginal simple main effect, such that skill-replacing automation leads to a general lower liking of the product compared with the baseline $(\mathrm{b}=-.25, \mathrm{t}(396)=-1.67, p=.097)$. No main effect of condition emerges for the comparison of the skill-allowing automation and baseline conditions $(p=.74)$. The interactions of identification with skill-replacing automation $(\mathrm{b}=-.51, \mathrm{t}(396)=-5.33, p<.001)$ and with skillallowing automation $(\mathrm{b}=-.23, \mathrm{t}(396)=-2.50, p=.013)$ are significant.

In support of our main hypothesis, stronger identification corresponds to greater liking in the no automation condition $(\mathrm{b}=.18, \mathrm{t}(133)=3.14, p<.01)$ but lower liking in the skill-replacing condition $(\mathrm{b}=-.33, \mathrm{t}(131)=-4.34, p<$ $.001)$. Also in line with our predictions, the negative association between strength of identification and liking does not appear in the skill-allowing automation condition $(\mathrm{b}=.06$, $\mathrm{t}(132)=-.86, p=.39)$. In other words, automation leads to lower liking among strong identifiers only if it is framed as replacing the user's skills. Further regression analyses and floodlight analyses help contrast the effect of identity on product liking across conditions.

No automation versus skill-replacing automation. A significant interaction emerges between identity strength and condition $(\mathrm{b}=-.51, \mathrm{t}(264)=-5.39, p<.001)$. A floodlight analysis reveals at which level of cooking identity $(\mathrm{M}=3.61$; $\mathrm{SD}=$ $1.59)$ the interaction becomes significant. Participants whose cooking identity score is 2.40 or less like the skill-replacing automated product more than the non-automated product $(\mathrm{b}=.36, \mathrm{SE}=.18)$, whereas those whose cooking identity score is 3.69 or more like the non-automated product more than the skill-replacing automated product $(\mathrm{b}=-.29, \mathrm{SE}=.15)$.

No automation versus skill-allowing automation. We find a significant interaction between identity strength and condition $(\mathrm{b}=-.12, \mathrm{t}(265)=-2.66, p=.008)$. A floodlight analysis shows that participants whose cooking identity score is 1.28 or below like the skill-allowing automated product more than the non-automated product $(\mathrm{b}=.49, \mathrm{SE}=.25)$. In contrast, participants whose cooking identity score is 4.91 or more like the non-automated product more than the automated product $(\mathrm{b}=$ $-.35, \mathrm{SE}=.18)$. However, this effect is weaker than the previous contrast of the non-automated with the skill-replacing automated product.

Skill-replacing automation versus skill-allowing automation. We uncover a significant interaction between identity strength and condition $(\mathrm{b}=.27, \mathrm{t}(263)=2.65, p=.008)$. The floodlight analysis shows that participants whose cooking identity score is 4.08 or more like the skill-allowing automation more than the skill-replacing version $(b=.33, \mathrm{SE}=.17)$. The effect that causes strong identifiers to dislike automation thus appears mitigated when the automation supports their skill, rather than replacing it (Figure 3).

In summary, Study 6 affirms that consumers who strongly identify as cooks are less attracted to automated kitchen equipment framed as replacing their relevant cooking skills. However, by advertising automated products as compatible with people's efforts to exhibit their cooking skills, marketers can counteract the detrimental effects of automation for strong identifiers.

\section{General Discussion}

Automation in consumer products is one of the most visible manifestations of how technology is changing people's lives. Despite the importance and increasing prevalence of automated products in the marketplace, academic research thus far has offered limited insights into the consequences of this trend for 


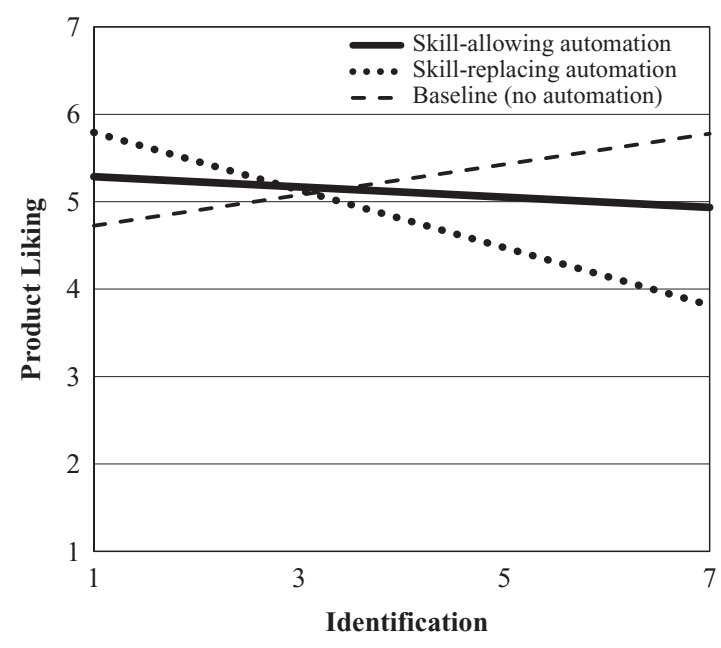

Figure 3. Study 6: Product liking by skill-replacing and skill-allowing automation condition.

consumers and marketers. The studies in this article start to address this gap. Automation provides great efficiency gains, making consumption more convenient and allowing consumers to enjoy the outcomes of consumption more readily. However, automation is not universally desirable; in particular, automated products can be unattractive when identity motives drive consumption. In a series of studies, we demonstrate that consumers who strongly identify with a social category tend to resist automation in identity-relevant products. When consumption requires performing non-trivial actions that involve skills or effort, automating the performance prevents consumers from attributing consumption outcomes to their own skills, ultimately depriving these identity-driven consumers of the self-signaling utility of consumption. To establish the managerial relevance and robustness of the findings, the studies span a variety of activities, automated features, and products: driving (automatic transmission, Study 1), biking (battery pack to assist pedaling, Studies 2 and 5), baking (bread-baking machine, Study 3), fishing (automatic hook setting, Study 4), and cooking (multipurpose cooking machine, Study 6). The data package is available at https://osf.io/xk7zt/.

\section{Theoretical Implications}

For decades, economists and sociologists have studied how automation affects employment and workers' well-being. We take a different perspective; instead of examining the supplyside effects of automation, we examine its demand-side implications. Our work focuses on consumers and the differential attractiveness of automated products for various types of consumers and their different consumption situations. In turn, we show that automation may increase the outcome utility of a product but decrease its self-signaling utility (Bodner and Prelec 2003), which is particularly relevant for identity-motivated consumers. Intriguingly, this proposition echoes the Marxist view of automation in production, which sees automation as alienating because it deprives workers of the self-rewarding features of their work (Blauner 1964; Braverman 1998). Our results also join a research stream in marketing that conceptualizes technological progress as a trend that, together with its obvious advantages, imposes challenges on consumers (Mick and Fournier 1998). In Etkin's (2016) study, participants wearing a pedometer walked more but reported less enjoyment from walking than participants who did not wear a pedometer. The current research also answers calls to explore how technology may affect people differently depending on their consumption motives (Reed et al. 2012).

Beyond a technology context, we contribute new theorizing on consumer identity. Identity-based consumer behavior is one of the most important areas of inquiry for consumer researchers, and decades of work have led to the accumulation of a vast and rich body of knowledge. The crux of this literature is that product choice and product use enable consumers to express who they are and the groups to which they belong (Belk 1988; Oyserman 2009a; Reed et al. 2012). Thus, consumers strategically choose products that others have not chosen to signal their identity (Berger and Heath 2007). However, identities affect not only product acquisition and display but also how consumers engage with products. We take an action-oriented perspective (Oyserman 2009b) and highlight that identity-based consumption relies on consumers being able to attribute the consumption outcomes to their own skills. Despite the advantages of automation, strong identifiers often resist products that automate skills central to their identity, because they appear tantamount to cheating.

\section{Managerial Implications}

Across product domains, companies are investing heavily in innovations to make consumers' lives easier. Our results do not question the marketplace value of automation but rather warn managers against thinking of automation as universally desirable. They thus have important implications for a range of marketing decisions.

Targeting. In many product categories, strong identifiers are highly involved consumers and prime targets for a company's most innovative (and expensive) products. Our findings highlight the risk of targeting strong identifiers with product innovations that involve the automation of identityrelevant tasks. Innovations that prevent internal attribution of consumption outcomes risk being unappealing to a firm's most attractive customers, which may help explain the low adoption rates of some innovative products, such as cooking machines among amateur cooks and knitting machines among knitting enthusiasts.

Product innovation. In addition to pointing to a potential reason for disappointing sales to strong identifiers, our studies offer suggestions for how to direct a company's innovation efforts. It is crucial to include an assessment of identity relevance when investigating which tasks, currently performed by consumers, 
could be good candidates for greater automation. We are not aware of any company currently performing such analyses systematically.

Communication. The way innovations are marketed also deserves careful attention. Automated products are not always preferable relative to their non-automated counterparts. For example, some cooking machines explicitly target cooking enthusiasts and stress how cooking could become a matter of "touching a button." Yet our results show that many potential customers value the opportunity to express their cooking skills, so marketers should not deprive them of the sense that they are responsible for producing the final outcome. In particular, Study 6 suggests that convenience is less of a selling point for strong identifiers than for the average customer. Marketers should take people's motives into account, then communicate the benefits of automation in a way that matches their target audience's goals.

\section{Further Research}

Similar to most phenomena with broad practical relevance, the effect of identity on preferences for automation likely reflects multiple determinants, and it would be interesting to assess the prevalence of other theoretical mechanisms. Our theorizing zooms in on the role of internal attribution, so we focus on documenting and isolating this factor, while minimizing the potential impact of other factors. A key mechanism that we have not discussed is the potential desire to learn skills by practicing, though not all of the products we investigate prevent such uses. For example, the bike battery pack in Studies 2 and 5 does not prevent people from exerting effort and practicing their cycling skills, and the automatic fishing hook in Study 4 still enables anglers to learn, because the automated feature is simply an addition to a normal fishing rod. Nonetheless, continued research might expand the nomological network we propose and examine other potential mediating processes.

The distaste for automation among strong identifiers is reminiscent of other situations in which people choose to forgo convenience. In a classic example, when General Mills launched Betty Crocker's instant cake mixes in the 1950s, sales initially were disappointing; they improved only when the product required the addition of an egg. Among the many explanations for the success of this strategy (e.g., cakes might be perceived as tastier or nutritionally richer with the addition of an egg), our results suggest that when users could not credit themselves for the cake, the mixes were not appealing. To determine whether resistance to convenience extends beyond automation, we also studied an actual coloring task (Web Appendix Q) and find that strong identifiers might dislike convenience that takes forms other than automation too, due to a similar internal attribution mechanism. Additional research should explore whether strategies to counteract the distaste for automation among strong identifiers might be applicable to cases in which tasks are outsourced to external agents. Furthermore, our results demonstrate that identifiers resist automation even when their choices are inconsequential or anonymous. Although this finding suggests that resistance to automation occurs even when choices are private, it might be amplified when choices are observable. Further research could explore other contextual determinants of how identity affects preferences for automation.

Methodologically, we use several procedures to ensure variance in the strength of identification. Measures of a chronic strength of identification (Studies 1 and 6) directly capture the extent to which different participants identify with a product category, but they require controlling for correlated constructs (e.g., expertise) that might also affect preferences for automation. Scenario procedures (Studies 3-5) allow for random assignments to conditions and facilitate stimuli that rule out alternative explanations. However, scenarios suffer from known limitations that should not be downplayed (e.g., they may tap into lay theories about behavior rather than actual behavior), and evidence from such studies does not reduce the need for more ecologically valid methods. Combining the advantages of these opposite approaches, the essay-writing manipulation in Study 2 is modeled after priming procedures (e.g., Puntoni et al. 2011) that attempt to activate existing identity-related knowledge structures through situational cues. Such manipulations allow for causal inferences about the population of interest, but they might be impractical to administer in certain studies, and populations in which the relevant latent identities are prevalent might be hard to reach. Our approach thus was to triangulate the findings obtained with different methods and across different contexts (product categories, stimuli, dependent variables, and participant populations). Further research also would benefit from improved solutions to the methodological trade-offs that characterize current research into the effects of strength of identification.

The ever-increasing range of tasks that machines can perform on consumers' behalf is a marker of technological development; we even might argue that automation defines progress, as washing machines did in the past and autonomous cars likely will in the near future. The recent explosion of computing and artificial intelligence promises the appearance of increasingly "skillful" products, capable of autonomous decision making and action. A fuller appreciation of how automation affects consumers' relationships with products thus is crucial for understanding how technology is likely to reshape consumption in the years ahead.

\section{Acknowledgments}

The authors thank Oleg Urminsky and the $J M R$ review team for their support and helpful comments.

\section{Authors' Contributions}

The authors contributed equally to this research and are listed in alphabetical order.

\section{Associate Editor}

James Bettman served as associate editor for this article. 


\section{Data Availability}

The data package is available at https://osf.io/xk7zt/.

\section{Declaration of Conflicting Interests}

The author(s) declare no potential conflicts of interest with respect to the research, authorship, and/or publication of this article.

\section{Funding}

The author(s) received no financial support for the research, authorship, and/or publication of this article.

\section{References}

Autor, David H. (2015), "Why Are There Still So Many Jobs? The History and Future of Workplace Automation," Journal of Economic Perspectives, 29 (3), 3-30.

Belk, Russell W. (1988), "Possessions and the Extended Self," Journal of Consumer Research, 15 (9), 139-68.

Bem, Daryl J. (1972), "Self-Perception Theory," in Advances in Experimental Social Psychology, Vol. 6, Leonard Berkowitz, ed. New York: Academic Press, 1-62.

Berger, Jonah and Chip Heath (2007), "Where Consumers Diverge from Others: Identity Signaling and Product Domains," Journal of Consumer Research, 34 (2), 121-34.

Blauner, Robert (1964), Alienation and Freedom: The Factory Worker and His Industry. Chicago: University of Chicago Press.

Bodner, Ronit and Drazen Prelec (2003), "Self-Signaling and Diagnostic Utility in Everyday Decision Making," in The Psychology of Economic Decisions, Vol. 1, Isabelle Brocas and Juan Carrillo, eds. Oxford: Oxford University Press, 105-26.

Braverman, Harry (1998), Labor and Monopoly Capital: The Degradation of Work in the Twentieth Century. New York: Monthly Review Press.

Brynjolfsson, Erik and Andrew McAfee (2014), The Second Machine Age: Work, Progress, and Prosperity in a Time of Brilliant Technologies. New York: WW Norton \& Company.

Chandler, Jesse J., and Gabriele Paolacci (2017), "Lie for a Dime: When Most Prescreening Responses Are Honest but Most Study Participants Are Impostors," Social Psychological and Personality Science, 8 (5), 500-508.

Cheng, Patricia W., and Laura R. Novick (1990), "A Probabilistic Contrast Model of Causal Induction," Journal of Personality and Social Psychology, 58 (4), 545-67.

Cutright, Keisha M., and Adriana Samper (2014), "Doing It the Hard Way: How Low Control Drives Preferences for High-Effort Products and Services," Journal of Consumer Research, 41 (3), 730-45.

Deshpandé, Rohit, Wayne D. Hoyer, and Naveen Donthu (1986), “The Intensity of Ethnic Affiliation: A Study of the Sociology of Hispanic Consumption," Journal of Consumer Research, 13 (2), 214-20.

Deshpandé, Rohit and Douglas M. Stayman (1994), "A Tale of Two Cities: Distinctiveness Theory and Advertising Effectiveness," Journal of Marketing Research, 31 (1), 57-64.

Erikson, Kai (1986), “On Work and Alienation," American Sociological Review, 51 (1), 1-8.
Etkin, Jordan (2016), "The Hidden Cost of Personal Quantification," Journal of Consumer Research, 42 (6), 967-84.

Faraji-Rad, A., Melumad S., and Johar G. V. (2017), "Consumer Desire for Control as a Barrier to New Product Adoption," Journal of Consumer Psychology, 27 (3), 347-54

Ford, Martin (2015). The Rise of the Robots, Technology and the Threat of Mass Unemployment. New York: Basic Books.

Frey, Bruno S., and Alois Stutzer (2005), "Beyond Outcomes: Measuring Procedural Utility," Oxford Economic Papers, 57 (1), 90-111.

Hayes, Andrew F. (2012), PROCESS: A Versatile Computational Tool for Observed Variable Mediation, Moderation, and Conditional Process Modeling. Available at: http://www.afhayes.com/public/ process2012.pdf.

Guiot, Denis, and Dominique Roux (2010), “A Second-Hand Shoppers' Motivation Scale: Antecedents, Consequences, and Implications for Retailers," Journal of Retailing, 86 (4), 355-71.

Khan, Uzma, and Ravi Dhar (2006), "Licensing Effect in Consumer Choice," Journal of Marketing Research, 43 (2), 259-66.

Loewenstein, George (1999), "Because It Is There: The Challenge of Mountaineering ... for Utility Theory," Kyklos, 52 (3), 315-43.

Marx, Karl (1844), The Economic and Philosophical Manuscripts. London: Penguin Books.

Menon, Tanya, Morris W. Morris, Chi-Yue Chiu, and Ying-Yi Hong (1999), "Culture and the Construal of Agency: Attribution to Individual Versus Group Dispositions," Journal of Personality and Social Psychology, 76 (5), 701-17.

Mezulis, Amy H., Lyn Y. Abramson, Janet S. Hyde, and Benjamin L. Hankin (2004), "Is There a Universal Positivity Bias in Attributions? A Meta-Analytic Review of Individual, Developmental, and Cultural Differences in the Self-Serving Attributional Bias," Psychological Bulletin, 130 (5), 711-47.

Mick, David G., and Susan Fournier (1998), "Paradoxes of Technology: Consumer Cognizance, Emotions, and Coping Strategies," Journal of Consumer Research, 25 (9), 123-43.

Mokyr, Joel, Chris Vickers, and Nicolas L. Ziebarth (2015), "The History of Technological Anxiety and the Future of Economic Growth: Is this Time Different?" Journal of Economic Perspectives, 29 (3), 31-50.

Oyserman, Daphna (2009a), "Identity-Based Motivation and Consumer Behavior," Journal of Consumer Psychology, 19 (3), 276-9.

Oyserman, Daphna (2009b), "Identity-Based Motivation: Implications for Action-Readiness, Procedural-Readiness, and Consumer Behavior," Journal of Consumer Psychology, 19 (3), 250-60.

Parasuraman, Raja, and Victor Riley (1997), "Humans and Automation: Use, Misuse, Disuse, Abuse," Human Factors, 39 (2), 230-53.

Peer, Eyal, Sonam Samat, Laura Brandimarte, and Alessandro Acquisti (2016), "Beyond the Turk: An Empirical Comparison of Alternative Platforms for Crowdsourcing Online Behavioral Research," Available at https://papers.ssrn.com/sol3/papers. cfm?\%20abstract_id=2594183.].

Puntoni, Stefano, Steven Sweldens, and Nader T. Tavassoli (2011), "Gender Identity Salience and Perceived Vulnerability to Breast Cancer," Journal of Marketing Research, 48(3), 413-24. 
Reed, Americus, Mark Forehand, Stefano Puntoni, and and Luk Warlop (2012), "Identity-Based Consumer Behavior," International Journal of Research in Marketing, 29 (4), 310-21.

Rifkin, Jeremy (1996), The End of Work. New York: Putnam.

Riis, Jason, Joseph P. Simmons, and Geoffrey P. Goodwin (2008), "Preferences for Enhancement Pharmaceuticals: The Reluctance to Enhance Fundamental Traits" Journal of Consumer Research, 35 (3), 495-508.

Stets, Jan E., and Peter J. Burke. (2000), "Identity Theory and Social Identity Theory," Social Psychology Quarterly, 63 (3), 224-37.

The Economist (2016), “Automation and Anxiety," http://www.econ omist.com/news/special-report/21700758-will-smarter-machines- cause-mass-unemployment-automation-and-anxiety], accessed June 25, 2016.

Van Osselaer, Stijn, Suresh Ramanathan, Margaret Campbell, Joel Cohen, Jeannette Dale, Paul Herr, Chris Janiszewski, Arie Kruglanski, Angela Lee, Stephen Read, J. Edward Russo, and Nader Tavassoli (2005), "Choice Based on Goals," Marketing Letters, 16 (3), 335-46.

Weiss, Liad, and Gita V. Johar. (2013), "Egocentric Categorization and Product Judgment: Seeing Your Traits in What You Own (and Their Opposite in What You Don't)," Journal of Consumer Research, 40 (1), 185-201.

Wilcox, Keith, and Andrew T. Stephen (2013), "Are Close Friends the Enemy? Online Social Networks, Self-Esteem, and Self-Control," Journal of Consumer Research, 40 (1), 90-103. 